\title{
Conservative Medroxyprogesterone Acetate Therapy in Early Stage of Endometrial Carcinoma Associated with Phosphatase and Tensin Homolog Expression
}

\author{
Kenji Niwa1,2*, Minako Mori², Tatsuhiko Miyazaki ${ }^{3}$, Takuji Tanaka4, Ken-Ichiro Morishige ${ }^{2}$ \\ ${ }^{1}$ Department of Obstetrics \& Gynecology, Gujo City Hospital, Gujo City, Japan \\ ${ }^{2}$ Department of Obstetrics \& Gynecology, Gifu University Graduate School of Medicine, Gifu City, Japan \\ ${ }^{3}$ Section of Pathology, Gifu University Hospital, Gifu University Graduate School of Medicine, Gifu City, Japan \\ ${ }^{4}$ Department of Diagnostic Pathology \& Research Center of Diagnostic Pathology, Gifu Municipal Hospital, Gifu City, Japan \\ Email: *kniwa.gujo913@gmail.com
}

How to cite this paper: Niwa, K., Mori, M., Miyazaki, T., Tanaka, T. and Morishige, K.-I. (2017) Conservative Medroxyprogesterone Acetate Therapy in Early Stage of Endometrial Carcinoma Associated with Phosphatase and Tensin Homolog Expression. Open Journal of Pathology, 7, 1-12.

http://dx.doi.org/10.4236/ojpathology.2017. $\underline{71001}$

Received: October 3, 2016

Accepted: December 5, 2016

Published: December 8, 2016

Copyright $\odot 2017$ by authors and Scientific Research Publishing Inc. This work is licensed under the Creative Commons Attribution International License (CC BY 4.0).

http://creativecommons.org/licenses/by/4.0/

\section{Open Access}

\begin{abstract}
Young patients with the endometrial cancer IA who desire to preserve fertility, can select the conservative therapy with progestin. However, the therapy involves risks of progression and relapse. We examined immunohistochemical analyses of phosphatase and tension homolog (PTEN) and p53 expressions to predict the early relapse, and pregnancy and delivery. Twenty women with endometrial cancer, FIGO IA (1988) (FIGO staging was essentially defined post-surgically), instead of the pathogical specimen before surgery without myometrial invasion were estimated by MRI under 40 years at Gifu University Hospital, Japan from 1988 to 2009. Patients were treated with medroxyprogesterone acetate (MPA, $400-600 \mathrm{mg} /$ day) for $4-10$ months, with whole wall endometrial curettage performed every four weeks. Response to the therapy, pregnancy, delivery and relapse of disease during follow-up over a 72-month period. Immunohistochemical expression of PTEN and p53 was also evaluated with pregnancy, delivery and relapse rate. All patients had pathological complete remissions within 4 - 10 months. Relapse rate was high (60\%) in more than 72 months. Immunohistochemical PTEN retain in tumor cells before MPA treatment (8/10) was significant better correlation with pregnancy and delivery rate than of lost cases $(1 / 5)$ in non-obese women $(\mathrm{P}<0.05)$. Conservative therapy is feasible in carefully selected young women with endometrial cancer without myometrial invasion. However, the relapse rate was high. In cases who desire to be a pregnant, an earlier infertility treatment may be considered especially for PTEN loss especially in nonobese cases.
\end{abstract}




\section{Keywords}

Endometrial Cancer, Medroxyprogesterone Acetate, Conservative Therapy, High Relapse Rate, PTEN Retain

\section{Introduction}

Young patients with stage IA adenocarcinoma of the endometrium, who wish to preserve their reproductive functions, can select the conservative therapy by medroxyprogesterone acetate (MPA) and whole wall curettages [1]-[7]. Most of these patients are able to become free of disease and have child-bearing capacity by the above therapy. Some of them can conceive after infertility treatment. However, relapse of the disease or complex atypical hyperplasia (CAH) occurs during a long-term follow-up observation, and sometimes need hysterectomy [6]. Sensitivity to progestin is thought to be related with the presence of estrogen receptor (ER)- $\alpha$ and progesterone receptor (PgR). Another direct anti-tumor effects of progestin without mediation of ER- $\alpha$ and PgR are also known [8]. However, molecular mechanism of progestin's anti-tumor effect on the endometrial carcinoma is not clearly understood.

Endometrial cancers have high rates of phosphatidylinotitol 3-kinase (PI3K)/Akt pathway alterations reported [9] [10]. The most common PI3K pathway alteration in endometrial cancer is phosphatase and tensin homolog (PTEN) loss, which occurs via mutation, methylation, or chromosomal loss, and is reported in over $50 \%$ of cases [11] [12] [13] [14]. PTEN protein can also lost through effects of microRNAs band and protein degradation [15].

Studies evaluating the correlation between PI3K aberrations and clinical outcome have reported discrepant results. Loss of PTEN protein expression has been reported to show a better favorable [16] [17] [18] or less favorable prognosis [19] [20] [21] [22].

Recently, there is a report that it should be divisible into obese and non-obese to consider clinical influence of PTEN loss/retain. PTEN loss in obese patients was associated with an improved outcome, while PTEN loss in non-obese those was associated with a worse one in endometrioid endometrial cancer [23].

A well-known tumor suppressor gene, p53 is reported to regulate PTEN transcription [24] and PTEN inhibits degradation of p53 [25]. However, the effects of progestins on the expression of PTEN and p53 in endometrial cancer have not been clarified.

In the present study, we have tried to clarify the effects of MPA on the expression of PTEN, p53, ER- $\alpha$ and PgR in young patients with endometrial cancers, in conjunction with the pregnancy, delivery and prolapse by dividing into the non-obese and obese patents in a single institute.

\section{Patients and Methods}

From January 1988 to December 2009, twenty endometrial cancer patients FIGO IA (1988) (FIGO staging was essentially defined post-surgically), instead of the pathological specimen before surgery were recruited to the study at the Department of Obstetrics 
\& Gynecology, Gifu University Hospital. Inclusion criteria were: (1) age younger than 40 years (at the diagnosis), (2) nulliparous, (3) confirmed endometrial adenocarcinoma with grade 1/2 differentiation, (4) presence of PgR, (5) normal serum 125 level (<35 $\mathrm{U} / \mathrm{ml}$ ), (6) absence of myometrial invasion or extra-uterine spread by vaginal ultrasound, and magnetic resonance imaging (MRI) and/or computed tomography (CT) and (7) having a strong desire to preserve fertility potential. Exclusion criteria were inadequate hepatic and renal function, and abnormality in blood coagulation tests and/or history of thrombosis. Using the WHO criteria and Kurman and Norris' criteria [26], gynecologic cytopathologist (KN) and pathologist (TM) independently reviewed the original histologic slides. PgR expressions of the tumor cells in the pathological specimens were examined immunohistochemically before starting therapy.

After approval from the Gifu University Hospital Ethical Committee and all patients provided informed consents about the risk for progression or relapse of the tumor and the research use of their samples, the conservative therapy started. Medroxyprogesterone acetate therapy (400 - $600 \mathrm{mg} / \mathrm{day}$, po) was commenced with whole wall endometrial curettage was performed once every four weeks. Treatment continued for at least four months, and for at least two months after disappearance of pathological abnormalities. Response was assessed by the pathological specimens obtained at curettage. After the documentation of pathologically complete remission, the patients were closely followed-up, with pelvic examination, and serial serum tumor markers (CA125). The median follow-up period was 140.0 months, ranging from 72 to 254 months, after the beginning of the conservative therapy at our hospital.

A four $\mu \mathrm{m}$ section was cut from the paraffin blocks of the whole wall curettage specimens. Each section was mounted on a silane-coated glass slide, deparaffinized, and soaked for $15 \mathrm{~min}$ at room temperature in $0.3 \% \mathrm{H}_{2} \mathrm{O}_{2}$ /methanol to block endogenous peroxidase. Sections were incubated with antibodies against PTEN (mouse monoclonal, PTEN A2B1 with dilution 1:50; Santa Cruz Biotechnology, Santa Cruz, CA), p53 (mouse monoclonal, DO-7 with dilution 1:200; Novocastra, Newcastle, UK), ER (mouse monoclonal, 1D5 with 1:200; DAKO, Glosrup, Denmark) and PgR (mouse monoclonal, pgR 636 with dilution 1:200; DAKO) overnight at $4^{\circ} \mathrm{C}$. The primary antibody was visualized using the Hstofine Simple Stain PO(M) kit (Nichirei, Tokyo, Japan) according to the instruction manual. The slides were counterstained with hematoxylin. Normal endometrial epithelium provided an internal positive control, and negative controls without addition of primary antibody showed low background staining in all cases. The PTEN was scored positive if it showed cytoplasmic staining in the entire tumor or majority of the tumor cells, and negative if it showed no cytoplasmic staining in the tumor cells [27]. Tumors that were PTEN negative as classified as PTEN loss. PTEN heterogeneous and PTEN positive tumors were classified as PTEN retained. The intensity of staining for p53, ER- $\alpha$ and PgR in tumor cells was scored (IHC score: 0 through 2) by two investigators (KN and TM) independently as follows: 0 , negative; $1+$, weakly positive; and strongly positive $2+$, when compared to the corresponding normal endometrial glandular epithelium.

In order to elucidate factors associated with responses to MPA or infertility treatment, correlation between the immunohistochemical findings and undergoing relapse 
or successful pregnancy was determined by dividing into non-obese $(\mathrm{BMI}<30)$ and obese (BMI $\geq 30$ ) patients, using chi-square test or Fisher's exact test. Those findings were also compared prior to and during MPA treatment using Wilcoxon singned-rank test. $P$ values less than 0.05 were considered statistically significant.

\section{Results}

Twenty patients with endometrial cancer received conservative MPA treatment. Patients' characteristics are summarized in Table 1. The patients' ages ranged 23 to 37 years old (average, $30.7 \pm 3.4$ ). Pathological diagnoses were 18 with endometrioid adenocarcinoma and two with adenosquamous cell carcinoma, their grades being 19 with G1 and one with G2. The patient's BMI ranged 17.1 to 42.2 (26.5 \pm 7.5$)$. Treated period ranged 4 to $11(6.3 \pm 1.5)$. In Figure 1, changes of the endometrial lesions on MRI (T2-weighted) in Case 19are shown. Pathological changes of the endometrial lesions in Case 1 were also shown in Figure 2.

Clinicopathological responses, relapse, marital status, pregnancy, delivery and hysterectomy are summarized in Table 1 . The patients were initially treated with MPA at $400-600 \mathrm{mg} /$ day at $4-11$ months. All cases were completely pathological remission after conservative therapy with MPA and whole wall curettages. Relapses, including CAH were observed 12 among twenty patients. Six cases (Cases 2, 4, 5, 9, 14, 16) were strongly desired to preserve fertility-function and re-selected the MPA therapy after relapses; four (Cases 1, 3, 6 and 8) underwent hysterectomy after relapses, meanwhile three cases (Case 4, 14 and 16) were treated conservative therapy after relapse and finally received hysterectomy. Eighteen patients attempted to pregnant, ten became pregnant and delivered (56\%). Only one (Case 4 ) refused all therapies after the second relapse, and finally died due to lung metastases. Other nineteen women showed no evidence of disease including after hysterectomy cases.

Immunohistochemical expressions of PTEN, p53, ER- $\alpha$ and PgR were performed. ER- $\alpha$ (Figure 3(a)), PgR (Figure 3(b)) and p53 (Figure 3(d)) expressions were observed in the nuclei, meanwhile PTEN expression was detected mainly in cytoplasm of endometrial glands (Figure 3(c)). Table 2 summarizes the immunohistochemical evaluation of pre- and under-MPA endometrial lesions in twenty cases. The expressions of the PTEN, p53, ER- $\alpha$ and PgR in the pre- and under MPA therapy pair samples were compared. MPA treatment significantly decreased the expressions of p53 $(P<$ $0.01)$, ER- $\alpha(P<0.05)$ and PgR $(P<0.01)$, respectively, by Wilcoxon's test. PTEN positive reaction was shown in the pre-MPA endometrial lesions in twelve cases. PTEN loss was observed in the eight cases in the pre-MPA endometrial lesions. The presence of strong expressions of p53 (IHC score 2) in pre-MPA treatment endometrial samples were observed in two cases, and positive were shown in six cases. The correlations between outcomes (pregnancy, delivery and relapse) and PTEN loss/retain and p53 expressions before MPA-treatment are shown in Table 3. In the non-obese patients, the proportion of pregnancy and delivery in PTEN retain cases $(8 / 10,80 \%)$ was significantly higher than that with PTEN loss cases $(1 / 5,20 \%, \mathrm{P}<0.05)$. Other relapse rates and $\mathrm{p} 53$ expressions could not be found in a tendency.

The expressions of the PTEN (Figure 4(a)), p53 (Figure 4(b)), ER- $\alpha$ (Figure 4(c)) 


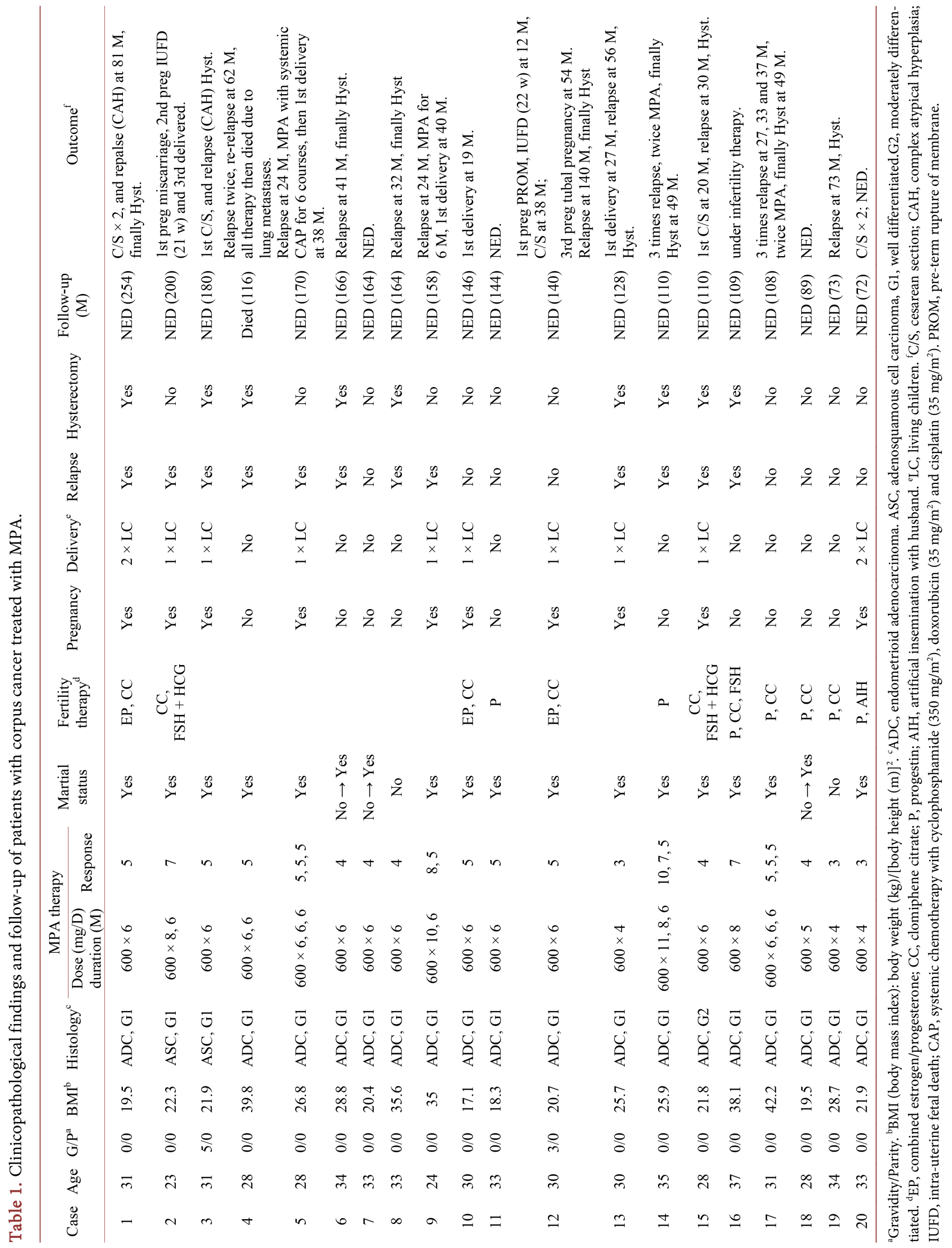



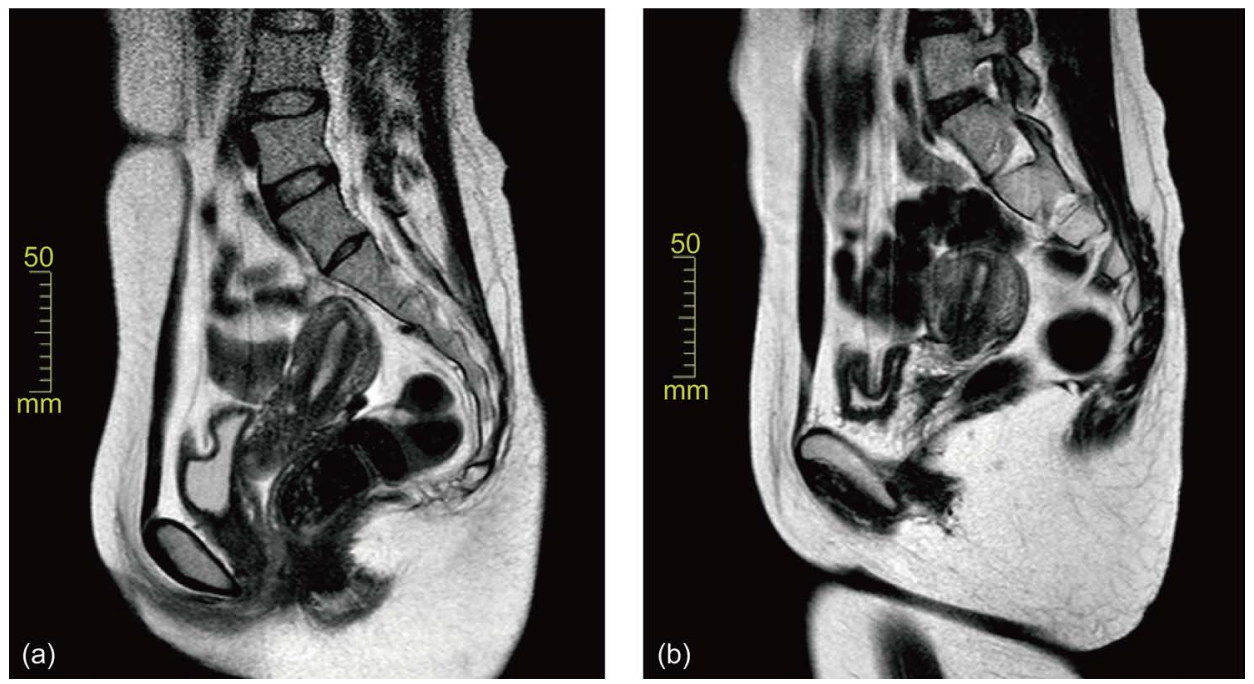

Figure 1. Changes of the endometrial lesions on the MRI (T2-weighted) in Case 19. (a) Before therapy, a slightly thickened endometrial lesion in seen; (b) the thickened lesion disappeared six months after the therapy.

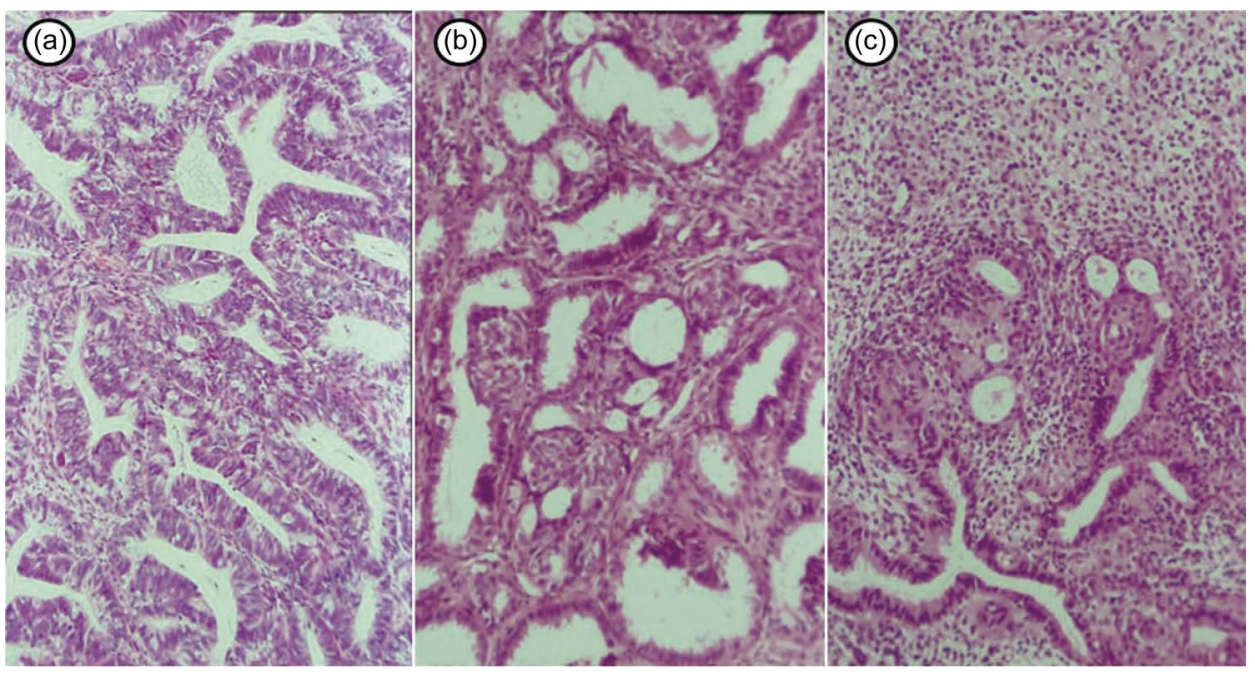

Figure 2. Pathological changes of endometrial lesions in Case 8. (a) Well-differentiated adenocarcinoma obtained by curettage before therapy; (b) degenerative atypical endometrial lesion obtained by endometrial curettage two months after the start of the therapy; (c) atrophic endometrium five months after the start of the therapy ( $\mathrm{H} \& \mathrm{E}$; magnification, $\times 85$ ).

and PgR (Figure 4(d)) in the pre- and under MPA therapy pair samples were compared. MPA treatment significantly decreased the expressions of p53 $(P<0.01)$, ER- $\alpha$ $(P<0.05)$ and $\operatorname{PgR}(P<0.01)$, respectively, by Wilcoxon's test.

\section{Discussion}

In the recent report, Wingless or PI3K/Akt alterations, including PTEN could not predict resistance to progesterone treatment in 6 responders and 5 non-responders [7]. However, all twenty cases had a pathologically complete response to MPA therapy and whole wall curettages, with subsequent term deliveries in ten women in the present study. Twelve out of 20 cases relapsed including CAH during the follow-up more than 


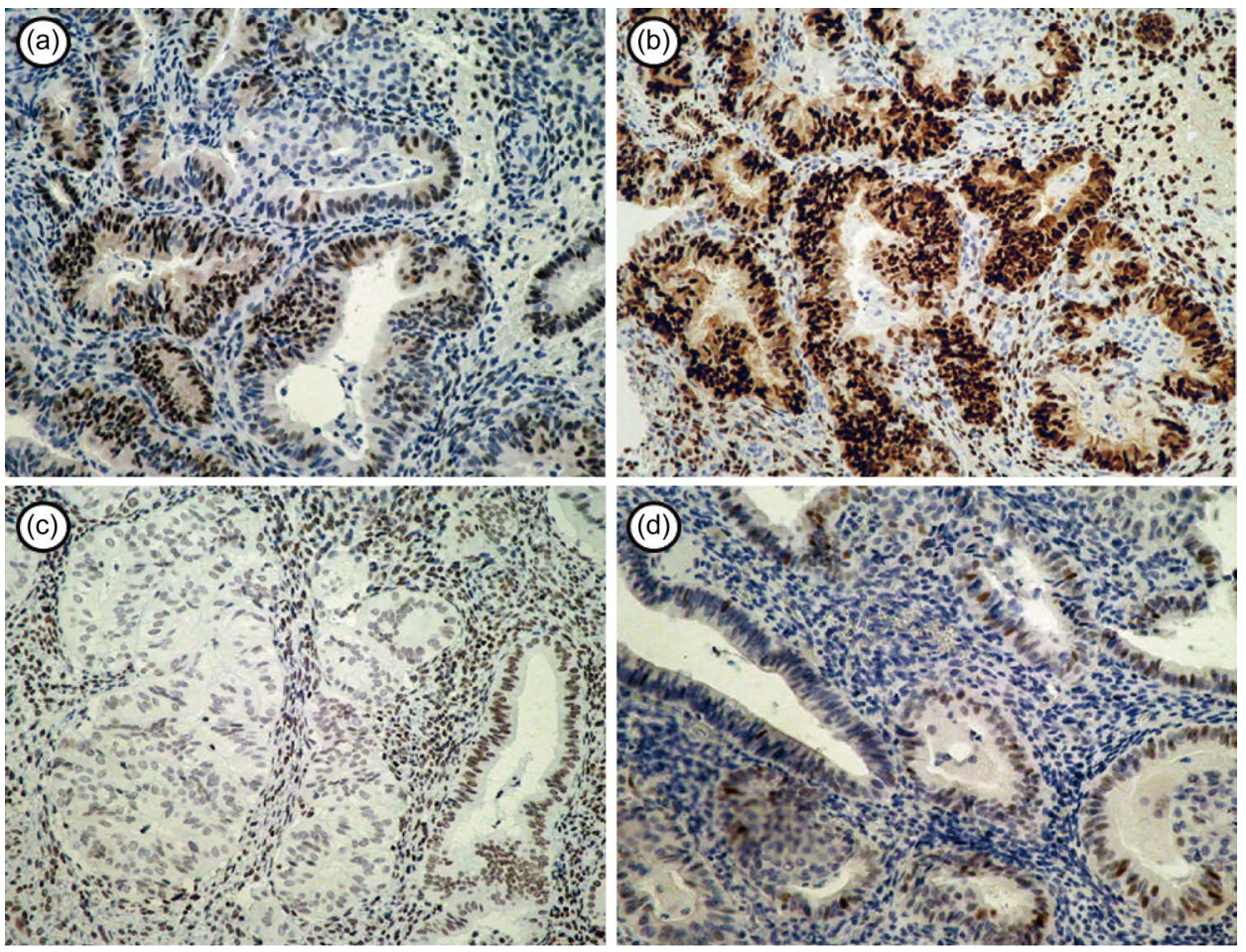

Figure 3. Immunohistochemical expression of the endometrial lesions before MPA-treatment. (a) Positive staining ER- $\alpha$ (IHC score $=2$ ); (b) positive staining of PgR (IHC = 2); (c) PTEN staining. Most of tumor cells were lost, but part of right tumor cells was retained. $\times 85$; (d) positive staining for $\mathrm{p} 53(\mathrm{IHC}=1) . \times 85$.

Table 2. Evaluation of PTEN, p53, ER and PgR before and under MPA therapy.

\begin{tabular}{|c|c|c|c|c|c|c|c|c|}
\hline \multirow{2}{*}{ Cases } & \multicolumn{4}{|c|}{ Before MPA therapy } & \multicolumn{4}{|c|}{ Under MPA therapy } \\
\hline & PTEN & p53 & ER- $\alpha$ & $\mathrm{PgR}$ & PTEN & p53 & ER- $\alpha$ & PgR \\
\hline 1 & loss & 0 & $1+$ & $1+$ & loss & 0 & $1+$ & 0 \\
\hline 2 & $1+$ & 0 & $1+$ & $1+$ & $1+$ & 0 & $1+$ & 0 \\
\hline 3 & $1+$ & 0 & $1+$ & $1+$ & $1+$ & 0 & $1+$ & 0 \\
\hline 4 & loss & 0 & $2+$ & $2+$ & loss & 0 & $1+$ & 0 \\
\hline 5 & $1+$ & 0 & $2+$ & $2+$ & $1+$ & 0 & $1+$ & 0 \\
\hline 6 & loss & 0 & $2+$ & $2+$ & loss & 0 & $2+$ & 0 \\
\hline 7 & loss & 0 & $2+$ & $1+$ & $1+$ & 0 & $2+$ & 0 \\
\hline 8 & $1+$ & 0 & $2+$ & $2+$ & $1+$ & 0 & $2+$ & $2+$ \\
\hline 9 & $1+$ & $2+$ & $2+$ & $2+$ & $1+$ & 0 & $2+$ & 0 \\
\hline 10 & $1+$ & 0 & $2+$ & $2+$ & $1+$ & 0 & 0 & 0 \\
\hline 11 & $1+$ & 0 & $2+$ & $2+$ & $1+$ & 0 & $1+$ & 0 \\
\hline 12 & $1+$ & $1+$ & $2+$ & $2+$ & $1+$ & 0 & $2+$ & 0 \\
\hline 13 & $1+$ & $1+$ & $2+$ & $2+$ & $1+$ & 0 & $1+$ & $1+$ \\
\hline 14 & loss & 0 & $2+$ & $2+$ & loss & 0 & $2+$ & 0 \\
\hline 15 & $1+$ & $2+$ & $2+$ & $2+$ & $1+$ & 0 & $2+$ & 0 \\
\hline 16 & loss & $1+$ & $2+$ & $2+$ & loss & 0 & $2+$ & $2+$ \\
\hline 17 & loss & $1+$ & $2+$ & $2+$ & loss & 0 & $1+$ & $1+$ \\
\hline 18 & $1+$ & 0 & $2+$ & $2+$ & 0 & 0 & $2+$ & $1+$ \\
\hline 19 & loss & $1+$ & $2+$ & $2+$ & loss & 0 & $2+$ & 0 \\
\hline 20 & $1+$ & $1+$ & $2+$ & $2+$ & $1+$ & 0 & $1+$ & 0 \\
\hline
\end{tabular}

IHC score: 0 , negative; $1+$, weakly positive; $2+$, strongly positive, compared to the corresponding normal endometrial epithelium. 
Table 3. Associations between immunohistochemical PTEN and p53 expressions, and outcome.

\begin{tabular}{|c|c|c|c|c|}
\hline & \multicolumn{2}{|c|}{ Pregnancy \& delivery } & \multicolumn{2}{|l|}{ Relapse } \\
\hline & No./Total & $P$ value ${ }^{\mathrm{a}}$ & No./Total (\%) & $P$ value \\
\hline \multicolumn{5}{|c|}{ Non-obese $(\mathrm{BMI}<30, \mathrm{n}=15)$} \\
\hline \multicolumn{5}{|l|}{ PTEN } \\
\hline loss & $1 / 5(20 \%)$ & 0.047 & $2 / 5(40 \%)$ & NS \\
\hline retain & $8 / 10(80 \%)$ & & $5 / 10(50 \%)$ & \\
\hline \multicolumn{5}{|l|}{$\mathrm{p} 53$} \\
\hline positive & $4 / 5(80 \%)$ & NS & $2 / 5(40 \%)$ & NS \\
\hline negative & $5 / 10(50 \%)$ & & $7 / 10(70 \%)$ & \\
\hline \multicolumn{5}{|c|}{ Obese $(\mathrm{BMI} \geq 30, \mathrm{n}=5)$} \\
\hline \multicolumn{5}{|l|}{ PTEN } \\
\hline loss & $0 / 3(0 \%)$ & NS & $2 / 3(67 \%)$ & NS \\
\hline retain & $1 / 2(50 \%)$ & & $2 / 2(100 \%)$ & \\
\hline \multicolumn{5}{|l|}{ p53 } \\
\hline positive & $1 / 3(33 \%)$ & NS & $2 / 3(67 \%)$ & NS \\
\hline negative & $0 / 2(0 \%)$ & & $2 / 2(100 \%)$ & \\
\hline
\end{tabular}

${ }^{\text {a }} P$ value was caluculated by Fisher's exact probability test.
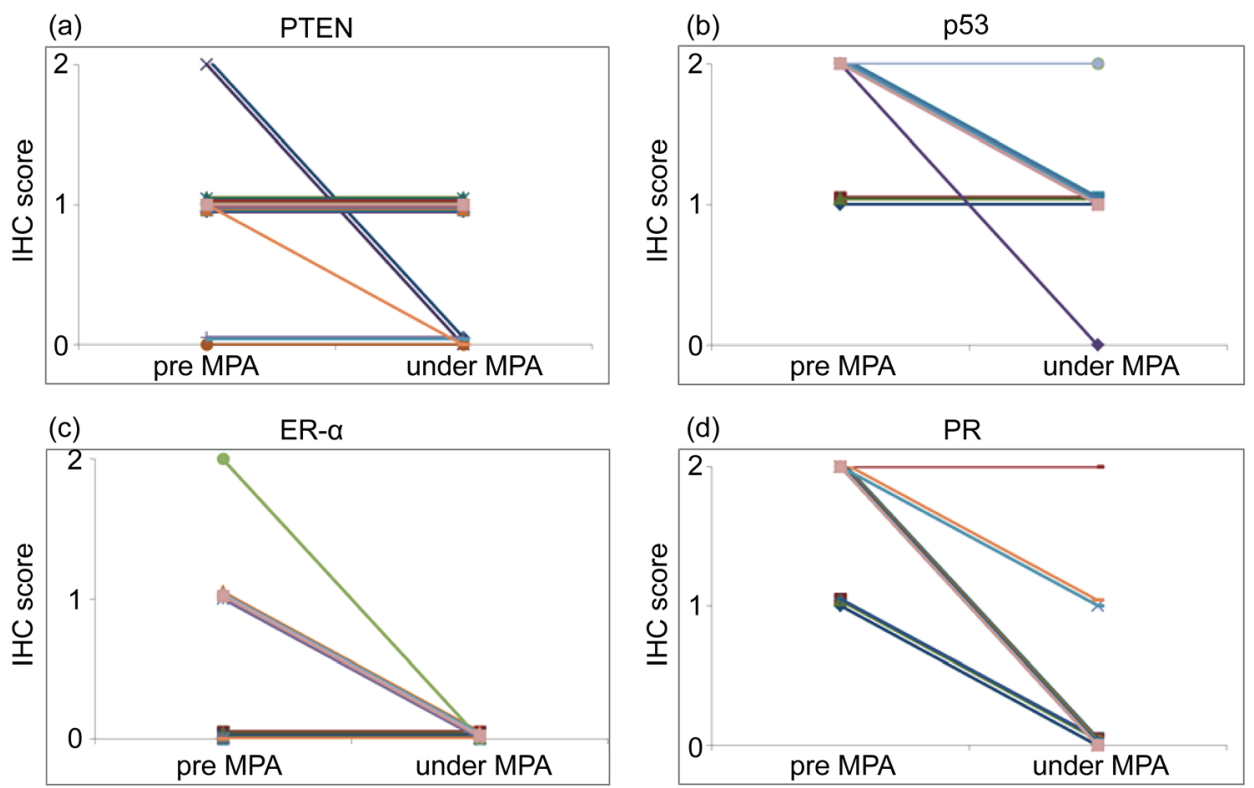

Figure 4. Comparison of immunohistochemical stainings of PTEN (a), p53 (b), ER- $\alpha$ (c), PgR (d), before and under MPA therapy. IHC scores are shown in Table 2. MPA treatment significantly decreased the expressions of p53 $(P<0.01)$, ER- $\alpha(P<0.05)$ and PgR $(P<0.01)$, respectively, by Wilcoxon's test (Figures $4(\mathrm{~b})-4(\mathrm{~d})$ ).

72 months. In non-obese cases, PTEN retain before MPA treatment showed a significant better pregnancy and delivery ratio than PTEN loss. In cases who desire to be a pregnant, an earlier infertility treatment might be considered especially for PTEN loss cases. When patients having term babies showed relapsed findings, we recommended to hys- 
terectomy and most of these agreed with our proposal. Only one case (Case 4) had refused all therapies, such as hysterectomy or hormonal therapies, and died due to lung metastases. Other nineteen cases lived under our observation even after hysterectomy cases.

PTEN mutation is highly observed in endometrial endometrioid adenocarcinoma, which is thought to be estrogen-dependent [28]. ER- $\alpha$ has been reported to bind in a ligand-dependent manner to $\mathrm{p} 85 \alpha$, the regulatory subunit of PI3K, leading to activate of Akt [29]. Thus, loss of PTEN function promotes the signal transduction of estrogen/ PI3K/Akt pathway. PTEN is mutated in 30\% - 55\% of endometrial carcinomas [11] [12] [13] [14] and also in approximate $20 \%$ of the endometrial precancerous endometrial lesions [30].Accordingly, inactivation of PTEN might be occurred in an early event in the endometrial carcinogenesis [31]. Many studies have investigated the relation of PTEN loss and endometrial cancer prognosis with discrepant results [16]-[22]. These differences are likely due to differences in the study methods, including the study population and PTEN antibodies. In our study, non-endometrioid and grade 3 were not included. Thus, in non-obese patients, PTEN retain in pre-MPA endometrial lesion was better correlation with pregnant and delivery rate, although the number is small.

Obesity among women of childbearing age can have a negative impact on fertility. The mechanism of action between obesity and infertility is complex and includes hormonal factors, alterations in ovulation, and changes in the menstrual cycle [32]. The relapse rate of non-obese and obese patients was high under the long follow-up in the present study. Many relapse patients needed hysterectomy. Thus, the pregnant and delivery rate in the PTEN retain before MPA treatment of non-obese patients was significant higher than that in PTEN loss. PTEN loss cases, who wish a baby, need earlier infertile treatment, compared with PTEN retain cases.

In our immunohistochemical study, the changes of PTEN IHC scores and PTEN loss endometrial glands cases in pre- and under MPA treatment were observed (Table 2). Our and Minaguchi's observation [14] changes of PTEN and PTEN loss gland expressions could not be found. Thus, PTEN loss cells may be resistant to MPA and survive even after MPA treatment, and might progress to persistent disease or early relapse.

In our study, p53 IHC scores significant decreased by the MPA-treatment $(P<0.01)$. Kester et al. reported that prolonged progestin treatment induced the promoter of p21 through p53 activation in endometrial tumor cells, and that the p53 activation by progestin may be caused by nuclear translocation of p53 [33]. Immunohistochemical p53 positive cells were thought to be in muted cells and phosphorylation or acetylation of p53 might be involved in its activation by long progestin treatment [34].

The expressions of ER- $\alpha$ and PgR before MPA-treatment could not be associated with pregnancy, delivery or prolapse. MPA treatment showed significant decreased expression of IHC scores in both ER- $\alpha$ and PgR levels $(P<0.05$ and $P<0.01$, respectively). The decreased expressions of ER- $\alpha$ and PgR by progestin were similar to decreased tendency in the endometrial hyperplasia [35]. The changes in receptor expressions might be thought as possible markers for therapy response [35]. Our all cases showed completely pathological CR after the MPA therapy, like as the responders in the endometrial hyperplasia cases. 


\section{Conclusion}

Young patients with early endometrial cancer may be cured by the MPA and whole wall curettage. However, prolapse rate was high under a long-term follow-up. In cases who desire to be a pregnant, an earlier infertility treatment may be considered especially for PTEN loss cases.

\section{References}

[1] Kaku, T., Yoshikawa, H., Tsuda, H., Sakamoto, A., Fukunaga, M., Kuwabara, Y., Hataeg, M., Kodama, S., Kuzuya, K., Sato S., Nishimura, T., Hiura, M., Nakano, H., Iwasaka, T., Miyazaki, K. and Kamura, T. (2001) Conservative Therapy for Adenocarcinoma and Atypical Endometrial Hyperplasia of the Endometrium in Young Women: Central Pathologic Review and Treatment Outcome. Cancer Letters, 167, 39-48. https://doi.org/10.1016/S0304-3835(01)00462-1

[2] Zheng, W., Baker, H.E. and Mutter, G.L. (2004) Involution of PTEN-Null Endometrial Glands with Progestin Therapy. Gynecologic Oncology, 92, 1008-1013. https://doi.org/10.1016/j.ygyno.2003.11.026

[3] Ramirez, P.T., Frumovitz, M., Bodurka, D.C., Sun, C.C. and Levenback, C. (2004) Hormonal Therapy for the Management of Grade 1 Endometrial Adenocarcinoma: A Literature Review. Gynecologic Oncology, 95, 133-138. https://doi.org/10.1016/j.ygyno.2004.06.045

[4] Niwa, K., Tagami, K., Lian, Z., Onogi, K., Mori, H. and Tamaya, T. (2005) Outcome of Fertility-Preserving Treatment in Young Women with Endometrial Carcinomas. BJOG, 112, 317-320. https://doi.org/10.1111/j.1471-0528.2004.00398.x

[5] Ushjima, K., Yahata, H., Yoshikawa, H., Konishi, I., Yasugi, T., Saito, T., Nakanishi, T., Sasaki, H., Saji, F., Iwasaki, T., Hatase, M., Kodama, S., Saito, T., Terakawa, N., Yaegashi, N., Hiura, M., Sakamoto, A., Tsuda, H., Fukunaga, M. and Kamura, T. (2007) Multicenter Phase II Study of Fertility-Sparing Treatment with Medroxyprogesterone Acetate for Endometrial Carcinoma and Atypical Hyperplasia in Young Women. Journal of Clinical Oncology, 25, 2798-2803. https://doi.org/10.1200/JCO.2006.08.8344

[6] Park, J.Y. and Nam, J.H. (2015) Progestins in the Fertility-Sparing Treatment and Retreatment of Patients with Primary and Recurrent Endometrial Cancer. Oncologist, 20, 270-278. https://doi.org/10.1634/theoncologist.2013-0445

[7] van Gent, M.D., Nicolae-Cristea, A.R., de Kroon, C.D., Osse, E.M., Kagie, M.J., Trimbos, J.B., Hazelbag, H.M., Smit, V.T. and Bosse, T. (2016) Exploring Morphologic and Molecular Aspects of Endometrial Cancer under Progesterone Treatment in the Context of Fertility Preservation. International Journal of Gynecological Cancer, 26, 483-490. https://doi.org/10.1097/IGC.0000000000000629

[8] Fournier, D.B., Chisamore, M., Lurain, J.R., Rademaker, A.W., Jordan, V.C. and Tonetti, D.A. (2001) Protein kinase C alpha Expression Is Inversely Related to ER Status in Endometrial Carcinoma: Possible Role in AP-1-Mediated Proliferation of ER-Negative Endometrial Cancer. Gynecologic Oncology, 81, 366-372. https://doi.org/10.1006/gyno.2001.6164

[9] Salvesen, H.B., Carter, S.L., Mannelqvist, M., Dutt, A., Getz, G., Stefansson, .M., Raeder, M.B., Sos, M.L., Engelsen, I.B., Trovik, J., Wik, E., Greulich, H., Bø, T.H., Jonassen, I., Thomas, R.K., Zander, T., Garraway, L.A., Oyan, A.M., Sellers, W.R., Kalland, K.H., Meyerson, M., Akslen, L.A. and Beroukhim, R. (2009) Integrated Genomic Profiling of Endometrial Carcinoma Associates Aggressive Tumors with Indicators of PI3 Kinase Activation. Proceedings of the National Academy of Sciences of the United States of America, 106, 4834-4839. https://doi.org/10.1073/pnas.0806514106

[10] Cheung, L.W., Henessy, B.T., Li, J., Yu, S., Myers, A.P., Djordjevic, B., Lu, Y., Stemke-Hale, K., Zhang, F., Ju, Z., Cantley, L.C., Scherer, S.E., Liang, H., Lu, K.H., Broaddus, R.R. and 
Mills, G.B. (2011) High Frequency of PI3KR1 and PI3KR2 Mutations in Endometrial Cancer Elucidates a Novel Mechanism for Regulation of PTEN Protein Stability. Cancer Discovery, 1, 170-185. https://doi.org/10.1158/2159-8290.CD-11-0039

[11] Kong, D., Suzuki, A., Zou, T.T., Sakurada, A., Kemp, L.W., Wakatsuki, S., Yokoyama, T., Yamakawa, H., Furukawa, T., Sato, M., Ohuchi, N., Sato, S., Yin, J., Wang, S., Abraham, J.M., Souza, R.F., Smolinski, K.N., Meltzer, S.J. and Horii, A. (1997) PTEN1 Is Frequently Mutated in Primary Endometrial Carcinomas. Nature Genetics, 17, 143-144.

https://doi.org/10.1038/ng1097-143

[12] Risinger, J.I., Hayes, A.K., Berchuck, A. and Barrett, J.C. (1997) PTEN/MMAC1 Mutations in Endometrial Cancers. Cancer Research, 57, 4736-4738.

[13] Tashiro, H., Blazes, M.S., Wu, R., Cho, K.R., Bose, S., Wang, S.I., Li, J., Parsons, R. and Ellenson, L.H. (1997) Mutations in PTEN Are Frequent in Endometrial Carcinoma But Rare in Other Common Gynecological Malignancies. Cancer Research, 57, 3935-3940.

[14] Minaguchi, T., Nakagawa, S., Takazawa, Y., Nei, T., Horie, K., Fujiwara, T., Osuga, Y., Yasugi, T., Kugu, K., Yano, T., Yoshikawa, H. and Taketani, Y. (2007) Combined PhosphoAkt and PTEN Expressions Associated with Post-Treatment Hysterectomy after Conservative Progestin Therapy in Complex Atypical Hyperplasia and Stage Ia, G1 Adenocarcinoma of the Endometrium. Cancer Letters, 248, 112-122.

https://doi.org/10.1016/j.canlet.2006.06.013

[15] Fata, J.E., Debnath, S., Jenkins Jr., E.C. and Fournier, M.V. (2012) Nongenomic Mechanisms of PTEN Regulation. International Journal of Cell Biology, 2012, Article ID: 379685. https://doi.org/10.1155/2012/379685

[16] Minaguchi, T., Yoshikawa, H., Oda, K., Ishino, T., Yasugi, T., Onda, T., Nakagawa, S., Matsumoto, K., Kawana, K. and Taketani, Y. (2001) PTEN Mutation Located Only Outside Exons 5, 6, and 7 Is an Independent Predictor of Favorable Survival in Endometrial Carcinomas. Clinical Cancer Research, 7, 2636-2342.

[17] Dellas, A., Jundt, G., Sartorius, G., Schneider, M. and Moch, H. (2009) Combined PTEN and $27^{\text {kip } 1}$ Protein Expression Patterns Are Associated with Obesity and Prognosis in Endometrial Carcinomas. Clinical Cancer Research, 15, 2456-2462. https://doi.org/10.1158/1078-0432.CCR-08-1732

[18] Mackay, H.J., Gallinger, S., Tsao, M.S., McLachlin, C.M., Tu, D., Keiser, K., Eisenhauer, E.A. and Oza, A.M. (2010) Prognostic Value of Microsatellite Instability (MSI) and PTEN Expression in Women with Endometrial Cancer: Results from Studies of the NCIC Clinical Trials Group (NCIC CTG). European Journal of Cancer, 46, 1365-1373. https://doi.org/10.1016/j.ejca.2010.02.031

[19] Kanamori, Y., Kigawa, J., Itamochi, H., Sultana, H., Suzuki, M., Ohwada, M., Kamura, T., Sugiyama, T., Kikuchi, Y., Kita, T., Fujiwara, K. and Terakawa, N. (2002) PTEN Expression Is Associated with Prognosis for Patients with Advanced Endometrial Carcinoma Undergoing Postoperative Chemotherapy. International Journal of Cancer, 100, 686-689. https://doi.org/10.1002/ijc.10542

[20] Salvesen, H.B., Stefansson, I., Kalvenes, M.B., Das, S. and Akslen, L.A. (2002) Loss of PTEN Expression Is Associated with Metastatic Disease in Patients with Endometrial Carcinoma. Cancer, 94, 2185-2191. https://doi.org/10.1002/cncr.10434

[21] Terakawa, N., Kanamori, Y. and Yoshida, S. (2003) Loss of PTEN Expression Followed by Akt Phosphorylation Is a Poor Prognostic Factor for Patients with Endometrial Cancer. Endocrine-Related Cancer, 10, 203-208. https://doi.org/10.1677/erc.0.0100203

[22] Athanassiadou, P., Athanassiades, P., Grapsa, D., Gonidi, M., Athanassiadou, A.M., Stamati, P.N. and Patsouris, E. (2007) The Prognostic Value of PTEN, p53, and Beta-Catenin in Endometrial Carcinoma: A Prospective Immunocytochemical Study. International Journal of Gynecological Cancer, 17, 697-704. https://doi.org/10.1111/j.1525-1438.2007.00845.x 
[23] Westin, S.N., Ju, Z., Broaddus, R.R., Krakstad, C., Li, J., Pal, N., Lu, K.H., Coleman, R.L., Hennessy, B.T., Klempner, S.J., Werner, H.M., Salvesen, H.B., Cantley, L.C., Mills, G.B. and Myers, A.P. (2015) PTEN Loss Is a Context-Dependent Outcome Determinant in Obese and Non-Obese Endometrioid Endometrial Cancer Patients. Molecular Oncology, 9, 1694-1703. https://doi.org/10.1016/j.molonc.2015.04.014

[24] Stambolic, V., MacPherson, D., Sas, D., Lin, Y., Snow, B., Jang, Y., Benchimol, S. and Mak, T.W. (2001) Regulation of PTEN Transcription by p53. Molecular Cell, 8, 317-325. https://doi.org/10.1016/S1097-2765(01)00323-9

[25] Mayo, L.D., Dixon, J.E., Durden, D.L., Tonks, N.K. and Donner, D.B. (2002) PTEN Protects p53 from Mdm2 and Sensitizes Cancer Cells to Chemotherapy. The Journal of Biological Chemistry, 277, 5484-5489. https://doi.org/10.1074/jbc.M108302200

[26] Kurman, R.J. and Norris, H.J. (1982) Evaluation of Criteria for Distinguishing Atypical Endometrial Hyperplasia from Well-Differentiated Carcinoma. Cancer, 49, 2547-2559. https://doi.org/10.1002/1097-0142(19820615)49:12<2547::AID-CNCR2820491224>3.0.CO; $\underline{2-0}$

[27] Garg, K., Broaddus, R.R., Soslow, R.A., Urbauer, D.L., Levine, D.A. and Djordjevic, B. (2012) Pathologic Scoring of PTEN Immunohistochemistry in Endometrial Carcinoma Is Highly Reproducible. International Journal of Gynecological Pathology, 31, 48-56. https://doi.org/10.1097/PGP.0b013e3182230d00

[28] Risinger, J.I., Hayes, K., Maxwell, G.L., Carney, M.E., Dodge, R.K., Barrett, J.C. and Berchuck, A. (1998) PTEN Mutation in Endometrial Cancers Is Associated with Favorable Clinical and Pathologic Characteristics. Clinical Cancer Research, 4, 3005-3010.

[29] Simoncini, T., Hafezi-Moghadam, A., Brazil, D.P., Ley, K., Chin, W.W. and Liao, J.K. (2000) Interaction of Oestrogen Receptor with the Regulatory Subunit of Phosphatidylinositol-3-OH Kinase. Nature, 407, 538-541. https://doi.org/10.1038/35035131

[30] Maxwell, G.L., Risinger, J.I., Gumbs, C., Shaw, H., Bentley, R.C., Barrett, J.C., Berchuck, A. and Futreal, P.A. (1998) Mutation of the PTEN Tumor Suppressor Gene in Endometrial Hyperplasias. Cancer Research, 58, 2500-2503.

[31] Kanamori, Y., Kigawa, J., Itamochi, H., Shimada, M., Takahashi, M., Kamazawa, S., Sato, S., Akeshima, R. and Terakawa, N. (2001) Correlation between Loss of PTEN Expression and Akt Phosphorylation in Endometrial Carcinoma. Clinical Cancer Research, 7, 892-895.

[32] Mitchell, A. and Fantasia, H.C. (2016) Understanding the Effect of Obesity on Fertility among Reproductive-Age Women. Nursing for Women's Health, 20, 368-376. https://doi.org/10.1016/j.nwh.2016.07.001

[33] Kester, H.A., Sonneveld, E., van der Saag, P.T. and van der Burg, B. (2003) Prolonged Progestin Treatment Induces the Promoter of CDK Inhibitor p21 ${ }^{\text {Cip1, Waf1 }}$ through Activation of p53 in Human Breast and Endometrial Tumor Cells. Experimental Cell Research, 284, 264273. https://doi.org/10.1016/S0014-4827(02)00017-4

[34] Brooks, C.L. and Gu, W. (2003) Ubiquitination, Phosphorylation and Acetylation: The Molecular Basis for p53 Regulation. Current Opinion in Cell Biology, 15, 164-171. https://doi.org/10.1016/S0955-0674(03)00003-6

[35] Vereide, A.B., Kaino, T., Sager, G., Arnes, M. and Ørbo, A. (2006) Effect of Levonorgestrel IUD and Oral Medroxyprogesterone Acetate on Glandular and Stromal Progesterone Receptors (PRA and PRB), and Estrogen Receptors (ER-Alpha and ER-Beta) in Human Endometrial Hyperplasia. Gynecologic Oncology, 101, 214-223.

https://doi.org/10.1016/j.ygyno.2005.10.030 
Submit or recommend next manuscript to SCIRP and we will provide best service for you:

Accepting pre-submission inquiries through Email, Facebook, LinkedIn, Twitter, etc. A wide selection of journals (inclusive of 9 subjects, more than 200 journals) Providing 24-hour high-quality service

User-friendly online submission system

Fair and swift peer-review system

Efficient typesetting and proofreading procedure

Display of the result of downloads and visits, as well as the number of cited articles Maximum dissemination of your research work

Submit your manuscript at: http://papersubmission.scirp.org/

Or contact ojpathology@scirp.org 